\title{
Correction to: The role of synthetic biology in climate change mitigation
}

Charles DeLisi

Correction to: Biol Direct (2019) 14:14

https://doi.org/10.1186/s13062-019-0247-8

After publication of this article [1], the author brought to our attention that there are some errors in the article.

The first error is in the equation of the footnote 1 . The correct equation should be: $\mathrm{C}=\exp (-\mathrm{t} / \mathrm{\tau})\left[\mathrm{C}_{0}-\mathrm{f} \tau \mathrm{R}_{0}\right.$ $\left.f \delta \tau^{2}\right]+f \tau[S(t)+\tau \delta](t<80$ years $)$, rather than $C=\exp (\tau$ $-\mathrm{t} /()\left[\mathrm{C}_{0}-\mathrm{f} \mathrm{\tau R} \mathrm{R}_{0}-\mathrm{f} \delta \mathrm{\tau}^{2}\right]+\mathrm{f} \tau[\mathrm{S}(\mathrm{t})+\mathrm{\tau} \delta](\mathrm{t}<80$ years $)$ in the previous publication.

The second error is in the beginning of the third line from the bottom of the footnote currently reads $\mathrm{dC} / \mathrm{dt}=$ $S(t)-C / \tau$ whereas it should read $d C / d t=f S(t)-C / \tau$.

The last error is the year in the last sentence of the response to Reviewer's report 2: it should be 2018 rather than 1918.

Published online: 29 November 2019

\section{Reference}

1. DeLisi C. The role of synthetic biology in climate change mitigation. Biol

Direct. 2019;14:14. https://doi.org/10.1186/s13062-019-0247-8. 